\title{
Prostate Stem Cells in the Development of Benign Prostate Hyperplasia and Prostate Cancer: Emerging Role and Concepts
}

\author{
Akhilesh Prajapati, ${ }^{1}$ Sharad Gupta, ${ }^{2}$ Bhavesh Mistry, ${ }^{1}$ and Sarita Gupta ${ }^{1}$ \\ ${ }^{1}$ Department of Biochemistry, Faculty of Science, The Maharaja Sayajirao University of Baroda, Vadodara, Gujarat 390005, India \\ ${ }^{2}$ Ex-assistant Professor karamsad medical college and Gupta Pathological laboratory, Vadodara, Gujarat 390001, India \\ Correspondence should be addressed to Sarita Gupta; sglmescrl@gmail.com
}

Received 23 April 2013; Revised 14 June 2013; Accepted 14 June 2013

Academic Editor: Mauro S. G. Pavao

Copyright (c) 2013 Akhilesh Prajapati et al. This is an open access article distributed under the Creative Commons Attribution License, which permits unrestricted use, distribution, and reproduction in any medium, provided the original work is properly cited.

Benign Prostate hyperplasia (BPH) and prostate cancer (PCa) are the most common prostatic disorders affecting elderly men. Multiple factors including hormonal imbalance, disruption of cell proliferation, apoptosis, chronic inflammation, and aging are thought to be responsible for the pathophysiology of these diseases. Both $\mathrm{BPH}$ and $\mathrm{PCa}$ are considered to be arisen from aberrant proliferation of prostate stem cells. Recent studies on $\mathrm{BPH}$ and PCa have provided significant evidence for the origin of these diseases from stem cells that share characteristics with normal prostate stem cells. Aberrant changes in prostate stem cell regulatory factors may contribute to the development of BPH or PCa. Understanding these regulatory factors may provide insight into the mechanisms that convert quiescent adult prostate cells into proliferating compartments and lead to $\mathrm{BPH}$ or carcinoma. Ultimately, the knowledge of the unique prostate stem or stem-like cells in the pathogenesis and development of hyperplasia will facilitate the development of new therapeutic targets for BPH and PCa. In this review, we address recent progress towards understanding the putative role and complexities of stem cells in the development of BPH and PCa.

\section{Introduction}

Prostate gland is a male accessory reproductive endocrine organ, which expels proteolytic solution in the urethra during ejaculation. In humans, the prostate is located immediately below the base of the bladder surrounding the neck region of the urethra. It is mainly associated with three types of disorders, namely, benign prostate hyperplasia $(\mathrm{BPH})$, prostate cancer (PCa), and prostatitis. $\mathrm{BPH}$ and $\mathrm{PCa}$ are the most common pathophysiological conditions of prostate gland in elderly men. These diseases already represent significant challenges for health-care systems in most parts of the world. Epidemiologically, $\mathrm{BPH}$ is more prevalent in Asian population $[1,2]$. Whereas, PCa is more common in the western world [3, $4]$. Both the diseases are complex and multifactorial. Factors predisposing to the development of $\mathrm{BPH}$ or $\mathrm{PCa}$ include hormonal imbalance, oxidative stress, environmental pollutants, inflammation, hereditary, aging, and, more particularly, stromal to epithelial cells crosstalk [5-7]. So far, variety of growth factors and hormonal factors, including androgens and estrogens, has been described in the hyperplastic development of the prostate gland [8-10]. However, the cellular and molecular processes underlying the pathogenesis and development of $\mathrm{BPH}$ or $\mathrm{PCa}$ are poorly understood.

Stem cells have an extensive capacity to propagate themselves by self-renewal and to differentiate into tissue-specific progeny. It is well know that stem cells are required to maintain and repair tissues throughout the lifetime. The requirement to understand the biology of stem cells derived from the prostate is increasing, as new evidence suggests that $\mathrm{BPH}$ and PCa may arise from the stem or stem-like cell compartments [11-13]. This review summarises the biology of prostate stem or stem-like cells and their contribution in pathogenesis and development of BPH and PCa.

\section{Prostatic Cellular Compartments}

The prostate is a hormonally regulated glandular organ whose growth accelerates at sexual maturity due to androgen action on both stromal and epithelial cells $[14,15]$. The human 


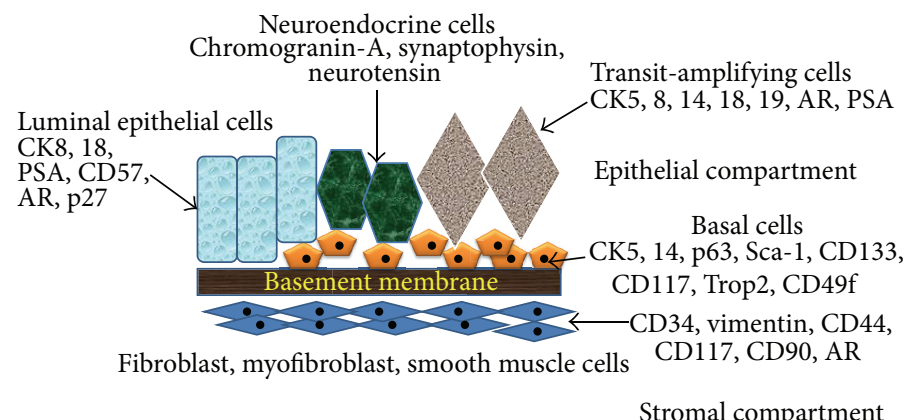

FIGURE 1: Prostatic cellular compartments and stem cell identity markers. Pictorial representation of different prostatic cells and their respective cellular markers.

prostate is a complex ductal-acinar gland that is divided into three anatomically distinct zones: peripheral, transitional, and central zones, which are surrounded by a dense and continuous fibromuscular stroma [16-18]. BPH, a nonmalignant overgrowth found in older men, mainly, develops in the transitional zone, while PCa arises primarily in the peripheral zone [19].

At histological level, human prostate contains mainly two types of cells that are called epithelial and stromal cells. The stromal to epithelial ratio in normal prostate of human is $2: 1$ $[18,20]$. The epithelial cell layer is composed of four differentiated cell types known as basal, secretory luminal, neuroendocrine (NE), and transit-amplifying (TA) cells that are identified by their morphology, location, and distinct marker expression (Figure 1). The basal cells form a layer of flattened to cuboidal shaped cells above the basement membrane and express p63 (a homolog of the tumor suppressor gene p53), Bcl-2 (an anti-apoptotic factor), Cluster designation (CD) 44 , hepatocyte growth factor (HGF), and the high molecular weight cytokeratins (CK) 5 and 14. The expression of androgen receptor (AR) is low or undetectable in the basal cells, which makes the basal cells independent of androgens for their survival [21-23]. The luminal cells are the major cell type of the prostate that form a layer of columnar-shaped cells above the basal layer and constitute the exocrine compartment of the prostate, secreting prostate-specific antigen (PSA) and prostatic acid phosphatase (PAP) into the lumen. They are terminally differentiated, androgen dependent, and nonproliferating cells, expressing low molecular weight CK8 and 18, CD57 and p27 ${ }^{\text {Kip1 }}$ (a cell cycle inhibitor) [22-24] along with high levels of AR. NE cells are rare cells scattered in the basal and luminal layers of the prostate. They are terminally differentiated and androgen-insensitive cells, expressing chromogranin A, synaptophysin, and neuron-specific enolase (NSF) $[23,25,26]$. The NE cells also produce and secrete neuropeptides such as bombesin, calcitonin, and neurotensin that are believed to support epithelial cell growth and differentiation $[19,27,28]$. Additionally, there is a small group of intermediate cells referred to as TA cells that express both basal as well as luminal cell markers (CK5, CK8, CK14, CK18, AR, and PSA) [29-32]. The epithelial layer is surrounded by a stromal layer, which forms a peripheral boundary of the prostate gland. The stromal cell layer consists of several types of cells that include smooth muscle cells (the most abundant cell type in stroma), fibroblasts, and myofibroblasts. Stromal cells express mesenchymal markers like CD34, vimentin, CD44, CD117, and CD90 [33].

\section{Stem Cell in Normal Prostate}

Prostatic epithelium is, structurally and functionally, a highly complex tissue composed of multiple differentiated cell types, including basal, luminal, and neuroendocrine cells, along with small population of relatively undifferentiated cells generally known as "stem cells" that are endowed with selfrenewal and differentiation capacities [26]. If the stem cells are key target for mutagenic changes and tumourigenesis in human prostate, we need to understand more about stem cell status in normal prostate tissue.

As the adult prostate is relatively slow-growing organ with limited cycles of cell proliferation and apoptosis, the possible existence of adult prostate stem cells (PSCs) was controversial for many years. Several investigations based on stem cell models have elegantly defined role of stem cells in cellular turnover and morphogenesis of normal prostate [30, 34]. Evidence for the existence of the stem cells in normal prostate came from the studies which demonstrated that adult rodent prostate can undergo multiple rounds of castration-induced regression and testosterone-induced regrowth [35-37]. Adult PSCs were believed to reside within the basal cell layer because of the ability of the basal cells to survive and undergo regression and regeneration following repeated castration and androgen replacement [38-40]. Adult mouse prostate epithelial cells, when transplanted along with the urogenital sinus mesenchymal cells under the renal capsule, generated normal murine prostate like structures [41]. Prostate glands were also regenerated when dissociated cells were implanted in Matrigel subcutaneously into immunodeficient mice [42]. Studies, including 5-bromo-2-deoxyuridine (BrdU) retention analysis, showed that the enriched population of BrdUlabelled cells possessing stem cell features (quiescent, high proliferation potential) are localized at the proximal region of mouse prostate duct [43] and are programmed to regenerate proximal-distal ductal axis [44]. The proximal region of the prostatic duct is surrounded by a thick band of smooth muscle cells [45] that are known to produce high level of transforming growth factor-beta (TGF- $\beta$ ) [46], which is known to play a critical role in maintaining the relative 
dormancy of the PSCs [47]. Independent study by Burger et al. also identified a candidate population of PSCs in the proximal region of mouse prostatic ducts, using stem cell surface marker known as stem cell antigen 1 (Sca-1, also known as Ly6a) [48]. In addition to high expression of Sca1 , these cells were shown to coexpress integrin $\alpha 6$ (CD49f) and Bcl-2. The cells with these properties showed a higher efficiency to generate prostatic tissue in an in vivo reconstitution assay [48]. Lawson et al. showed that sorting prostatic cells for CD45(-)CD31(-)Ter119(-)Sca-1(+)CD49f(+) antigenic profile results in a 60 -fold enrichment for colony and sphere-forming cells that can self-renew and expand to form spheres for many generations [49]. Leong and colleagues identified CD117 (c-Kit, stem cell factor receptor) as a new marker of a rare adult mouse PSC population that showed all the functional characteristics of stem cells including self-renewal and full differentiation potential. The CD117(+) single stem cell defined by the phenotype Lin(-)Sca-1(+)CD133(+)CD44(+)CD117(+) regenerated functional, secretion-producing prostate after transplantation in vivo. Moreover, CD117(+) PSCs showed long-term self renewal capacity after serial isolation and transplantation in vivo. CD117 expression was predominantly localized to the proximal region of the mouse prostate and was upregulated after castration-induced prostate involution, consistent with prostate stem cell identity and function [50].

Stem cells in the human prostate have been identified and isolated using the cell surface markers such as integrin $\alpha 2 \beta 1$ [51], CD133 (Prominin-1) [52], and CK6a (cytokeratin 6a) [53]. Based on high expression of $\alpha 2 \beta 1$ integrin, Collins and colleagues identified PSCs in the basal layer and showed that the $\alpha 2 \beta 1^{\text {high }}$ integrin cells represent $\sim 1 \%$ of basal cell population in the human prostate [51]. This selected PSC population was enriched through rapid adherence to the type I collagen and showed higher colony-forming efficiency in vitro. Furthermore, when the $\alpha 2 \beta 1^{\text {high }}$ integrin cells were grafted subcutaneously together with stromal cells in Matrigel into nude mice, they formed prostatic gland structures in vivo. Nevertheless, these glandular-like structures, although containing basal cytokeratin positive as well as AR, PAP, and PSA positive cells, lack well-defined basal and luminal organizations [51]. However, recent studies by Missol-Kolka et al. have reported that the overall expression of CD133 in human prostate is not strictly limited to the rare basal stem and progenitor cells, but it is also expressed in some of the secretory luminal cells [54]. Furthermore, it has been shown that CD133 is downregulated in prostate cancer tissues and upregulated in the luminal cells in the vicinity of cancer area. In contrast to the human CD133, the mouse CD133 has been shown to express widely in prostate [54]. Several other surface markers, such as aldehyde dehydrogenase (ALDH), tumor-associated calcium signal transducer 2 (Trop-2), ATP-binding cassette transporter family membrane efflux pump (ABCG2), p63, and CD44, have also been reported for identification and isolation of the PSCs from the prostate tissues of human and mouse [49, 55-60]. Moreover, Trop2(+)CD44(+)CD49f(+) were used as the markers to identify basal stem cells with enhanced prostasphere-forming and tissue-regenerating abilities [61]. Unlike the murine PSCs, the human PSCs are randomly distributed within the basal epithelial layer throughout the acini and ductal regions of the prostate [51, 52]. In addition to the expression of stemcell-specific markers, different studies have also shown that PSCs express both basal and luminal cell-specific markers in fetal and adult stages of prostate development $[13,22,31,62$, 63]. Several studies have proposed the existence of different cell compartments based on stem-cell-driven differentiation hierarchical arrangements within the prostate epithelium [24, $29,30,64]$.

In addition to prostate epithelial stem cells, stromal stem cells (SSCs) have also been reported to exist in the prostate, where they are postulated to carry out function of replacing and regenerating local cells that are lost to normal tissue turnover, injury, or aging [65-67]. These subpopulation of SSCs expressed mesenchymal stem cell (MSC) markers such as CD34 and Sca-1, showed a high proliferative activity and ability to differentiate into fibroblastic, myogenic, adipogenic, and osteogenic lineages [68]. Of all these potential lineages, the most characteristic cell type derived from prostate stromal stem cell is fibroblast or smooth muscle cells $[68,69]$. Growth factors that have regulatory effects on SSCs include members of TGF- $\beta$ superfamily, the insulin-like growth factors, the fibroblast growth factors, the platelet-derived growth factor, and Wnts [70]. It is believed that the differentiation of stromal stem cells to smooth muscle cells is due to paracrine effects of prostrate epithelial cells, which permanently commit the stromal stem cells to mature into androgen receptor (AR) expressing smooth muscle cells [68].

\section{Stem Cell in Benign Prostate Hyperplasia (BPH)}

$\mathrm{BPH}$ is a slow progressive enlargement of the prostate gland which can lead to lower urinary tract symptoms (LUTS) in elderly men. It is characterized by hyperproliferation of epithelial and stromal cells in the transition zone of the prostate gland, which can be observed histopathologically [71]. Despite of its obvious importance as a major health problem, little is known in terms of biological processes that contribute to the development of BPH. To explain the etiology behind the pathogenesis of $\mathrm{BPH}$, several theories, including stem cell, hormonal imbalance, apoptosis, epithelialmesenchymal transition, embryonic awakening, and inflammation, have been proposed in recent years, and all of them seem to contribute together to some extent in the pathogenesis of $\mathrm{BPH}[12,72]$. According to stem cell theory, the stem cell population residing in the prostate gland is increased due to abnormal proliferation and apoptosis of stem cells, which may eventually contribute to BPH pathogenesis. Earlier, it was reported by Berry et al. that stem cell population is responsible for prostate gland maintenance [73]. Changes in tissue consistency and cellular hyperplasia are accompanied by downregulation of apoptotic factors and increased level of antiapoptotic factors that decrease the rate of prostatic cell death and, thus, contributing to hyperproliferation of prostatic tissue [74]. It has been reported that stromal to epithelial 
ratio is altered in $\mathrm{BPH}$, where the ratio increases from $2: 1$ in normal glands to $5: 1$ in $\mathrm{BPH}$ [75]. Because stromal hyperproliferative activity is thought to promote the development of $\mathrm{BPH}$, the existence of adult stem cells in the prostate stromal compartment is speculated to expand the stroma in response to stimuli during the pathogenesis of $\mathrm{BPH}$ [68]. Lin et al. showed that primary culture of prostate cells from $\mathrm{BPH}$ patients possessed many common stem cell markers, including CD30, CD44, CD54, neuronspecific enolase (NSE), CD34, vascular endothelial growth factor receptor-1 (Flt-1), and stem cell factor (SCF, also known as KIT ligand or steel factor) [68]. Compared to CD30, CD44, CD54, and NSE, the CD34, Flt-1, and SCF markers were expressed at low level. These stem cells were negative for CD11b, stem cell antigen1 (SCA-1), SH2, AA4.1, and c-Kit. Furthermore, among this stem cell population only a fraction (5\%) of the stem cells was positive for CD133 [68]. Although the origin of these stem cells is not known, the CD49(+)CD54(+)NSE(+)SCF(+) cell marker profile of these cells suggests that they are in a lineage closely related to MSCs. The stem cell population with the above profile possessed ability to differentiate or transdifferentiate into myogenic, adipogenic, and osteogenic lineages $[68,76]$. Ceder et al. reported the possible existence of prostate stromal stem/progenitor cells in the adult human prostate [76]. This stromal population expressed vimentin (a mesenchymal marker), CD133, c-Kit, and SCF, with expression profiles similar to those observed in the Cajal cells of gastrointestinal tract, which represent a subset of stem cell-like cells. Several studies have identified c-Kit-expressing interstitial cells in the stromal compartment of human prostate [7779]. Altered patterns of c-Kit expression have been reported in benign lesions of prostate and breast tissues [80, 81]. It has been shown that the c-Kit expression and number of c-Kit(+) interstitial cells were significantly higher in $\mathrm{BPH}$ than those of the normal prostate. Furthermore, it has been suggested that $\mathrm{c}$-Kit regulates cell proliferation in prostate and plays a crucial role in the pathophysiology of $\mathrm{BPH}$ via altering the expression of JAK2 and STAT1 [77].

Stem cells from the BPH samples expressing CD49f, CD44, or CD133 markers have been shown to possess monolayer- and spheroid-colony-forming ability, where the highest (98\%) recovery of colony-forming cells (CFCs) was achieved by CD49f(+) cells as compared to CD44(+) (17\%) or CD133(+) (3\%) cells [82]. These CFCs showed the capacity to undergo clonal proliferation, generates branching ductal structures, and they expressed both basal and luminal lineage markers. Further characterization of CD49f(+) cells revealed that they are comprised of two cell types: CK5(+) basal epithelial cells and CD31(+) endothelial cells [82]. Sca-1- and CD34expressing cells isolated from BPH tissue showed a high proliferative capacity and increased plasticity, as these cells were able to differentiate into fibroblastic, myogenic, adipogenic and osteogenic lineages, similar to that of MSCs [68, 83]. Furthermore, Burger and colleagues found that cells with high Sca-1 expression had considerably more growth potential, and proliferative capabilities than cells expressing low or no Sca-1 antigen [48]. Expression of pluripotency markers such as $\operatorname{Oct} 4 \mathrm{~A}$, Sox2, $c-M y c$, and Klf4 might represent a stemnessspecific gene signature. A very recent study has demonstrated a relatively high expression of stemness-associated genes, including Oct4A, Sox2, c-Myc, Nanog, and Klf4, in BPH as compared to normal prostate tissue [84]. Thus, several studies have revealed the presence of stem cells that express pluripotency-associated markers and are hyperproliferative and capable of differentiation into different cell lineages within the hyperplastic prostate tissue. The presence of these high proliferative and plastic stem cells in the BPH tissue samples suggests that BPH could occur as a result of changes in the stem cell properties that could ultimately give rise to a clonal expansion of cell populations.

\section{Stem Cell in Prostate Cancer (PCa)}

PCa is the most prevalent and is the second most frequently diagnosed cancer and sixth leading cause of cancer-related deaths among men in the world [85]. Its etiology, although not clear, is partly attributed to multigenic and epigenetic mechanisms and the heterogeneous nature of this disease [4, 86-88]. Gleason and others described that when the transition of normal gland into adenocarcinoma of prostate takes place, its normal histological structure is disrupted and results in abnormal proliferation of the glandular structure, destruction of basement membrane, and progressive loss of basal cells $(<1 \%)[87,89]$. In addition, $\operatorname{AR}(+)$ luminal cells increase and contribute in bulk of prostate mass (>99\%) in $\mathrm{PCa}$ [90]. It is hypothesised that prostate cancer arises from $\mathrm{AR}(+)$ luminal cells and dramatic loss of basal cells. To support this hypothesis several investigations have been conducted [4, 91-93]. In addition, mouse basal population expressing $\operatorname{Lin}(-) \mathrm{Sca}-1(+) \mathrm{CD} 49 \mathrm{f}^{\text {high }}$ cells can differentiate into luminal cells in xenograft [49]. Lin(-)Sca-1(+)CD49f high cells from a Pten-/- mouse model display cancer stem cells phenotypes, which gave rise to adenocarcinoma after transplantation [94]. It has been reported that basal cells are the possible cells of prostate cancer origin [95]. When Goldstein et al., especially injected the mixture of urogenital sinus mesenchyme (UGSM) with human prostate basal (expressing CD49f $\mathrm{f}^{\text {high }}$ and Trop2 ${ }^{\text {high }}$ ) or luminal cells (expressing CD49f ${ }^{\text {low }}$ and Trop2 ${ }^{\text {high }}$ ) into the subcutaneous space of immunodeficient $\mathrm{NOD}(-) \operatorname{SCID}(-) \operatorname{IL}(-) 2 \mathrm{Rg}-/-$ mice, only basal cells formed prostatic duct after 16 week, whereas no prostatic duct or adenocarcinoma developed when using luminal cells $[91,95]$. Luminal derived grafts lack epithelial structures and mimicked transplantation of UGSM cell alone [95]. Collins et al. reported basal cancer stem cells isolated from human prostate cancer biopsies expressing Cd44(+), $\alpha 2 \beta 1^{\text {high }}$, and Cd133(+) and cell surface markers were of self renewal in vitro [96]. ALDH ${ }^{\text {high }}$ is another marker used for cancer stem cells in human prostate cancer cell lines. Cells expressing $\mathrm{ALDH}^{\text {high }} \alpha 2(+) / \alpha 6(+) / \alpha \mathrm{v}(+)$-integrin $\mathrm{CD} 44(+)$ showed increased tumourigenicity and metastasis in vivo and enhanced invasiveness in vitro [97]. Prostate cancer stem cells isolated from LNCaP and DU145 cell lines also showed expression of CD $44(+), \alpha 2 \beta 1^{\text {high }}$, and CD133(+) markers [98, 99]. In addition, CD44(+) population isolated from xenograft human tumour and cell lines displayed high tumour initiating 
ability and metastasis in vitro [100]. Recently, Rajasekhar and his group isolated a small cell population expressing TRA1-60(+)CD151(+)CD166(+) markers that displayed stem cell like features with increased NF-kB signalling along with basal cell markers, and this recapitulates the cellular hierarchy of the tumour origin from basal cells [101].

Over all data from several investigators indicated that origin of prostate cancer can be from basal stem cell population, which expresses CD44(+), $\alpha 2 \beta 1^{\text {high }}$, CD133(+), ALDH $^{\text {high }}$, and other normal basal stem cell markers.

\section{Stem Cell Niche and Plasticity}

Stem cells are localized in a defined microenvironment, which is known as their "niche." The main function of a niche probably is to provide specific factors necessary for the maintenance of the stem cell properties via a combination of intracellular and intercellular signalling. These factors include a complex array of growth factors, cytokines, chemokines, and adhesive molecules known to be capable of altering the balance between proliferation, differentiation, and quiescence in stem cell populations $[102,103]$. One can probably assume that this is equally true for prostatic stem cells as it is for other stem cell populations.

PSCs reside in niche areas within the basal layer of the epithelial compartment at a low percentage of approximately $0.5-1 \%$ [34]. PSCs population in the prostate undergoes a series of phenotype changes. Specifically, the basal SCs do not express the AR or the $\mathrm{p} 63$ protein. They have extended proliferative potential by slow cycling. According to these studies, it is postulated that, in addition to the reserve stem-cell population, there is a "TA" cell type, which is characterized by the expression of p63, as well as other basal markers such as CK5 and 14, Jagged-1, and Notch-1 $[64,104,105]$. A TA cell does not express AR protein and it is dependent, for proliferation, but not for survival, on andromedans secreted by stromal cells [105]. Under normal conditions a PSC is slow cycling in that it divides occasionally, undergoing asymmetric division to give rise to a new PSC along with a more differentiated TA daughter cell. TA cell undergoes a limited number of rapidly amplifying cell division cycles to increase the cell population derived from a single PSC before leaving the proliferative compartment to produce intermediate cell [106]. This intermediate cell expresses both epithelial specific (CK5 and 14) and luminal specific (CK8 and 18) cytokines, AR mRNA (but not protein), and prostate stem cell antigen (PSCA) $[105,107]$. As an intermediate cell migrates through the basal layer, it differentiates into various terminally differentiated cell lineages of prostate epithelium.

\section{Is BPH/PCa a Stem Cells Disease?}

Numerous investigators demonstrated presence of stem cell in prostate tissue by using various high-end techniques that may contribute to local invasive to metastatic disease in human and research animals. In normal tissue-development, homeostasis is maintained by differentiation of stem cells and

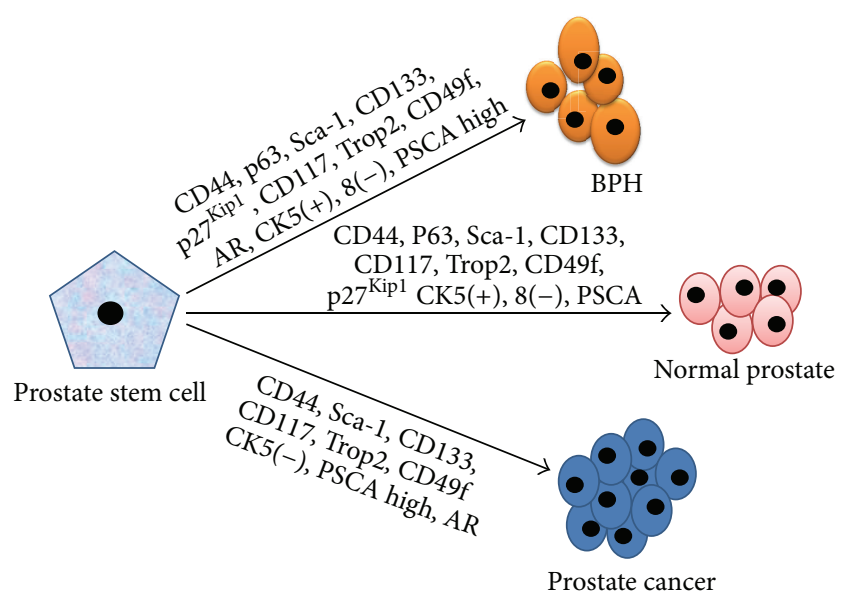

FIGURE 2: Cellular identity of stem cells in prostate. Stem cell model of normal tissue renewal, $\mathrm{BPH}$ and $\mathrm{PCa}$.

programmed cells death in regular cell cycle. This mechanism is established through interactions with tissue specific environmental factors such as growth factors and steroid hormones. Many signalling molecules and factors involvement have been reported in stem cell self-renewal and implication in cancer stem cells (CSCs) regulation (Figure 2).

Although the precise role of stem cells in tumourigenesis is still in debate, it is widely accepted that cancers can arise from normal stem cells which may accumulate mutation, genetic changes, and molecular pathway alterations that disrupt self-renewal control capacity (Table 1). It has been reported that, in prostate, putative stem/progenitor cells can reside in CK5(+) 8(-) basal cells. A diagnostic feature of human prostate cancer is the loss of basal cells [108], indicating cancer origin cells as basal cells. In $\mathrm{BPH}, \mathrm{CD} 133(+)$ cells expressed genes related to undifferentiated cells such as TDGF1 (teratocarcinoma-derived growth factor 1) and targets of the Wnt and Hedgehog developmental pathways, whereas CD133(-) cells showed upregulation of genes related to proliferation and metabolism. In cancer, CD133(+) cells specifically displayed more TA population phenotype with increased metabolic activity and proliferation, possibly explaining the transition from a relatively quiescent state to an active growing tumour phenotype. This reflects that CD133 isolates from benign and malignant tissues show biologically distinct characteristics [109]. CSCs exploit many of the signal pathways such as notch, hedgehog- and TGF- $\beta$, which play, important role in proliferation and differentiation in prostate stem cell $[110,111]$. The sonic hedgehog signalling element receptor PTCH1 and glioma-associated oncogene homolog-1 (GL1) transcription factor were especially reported to be colocalized with p63 basal marker in BPH and PCa cells, expressing CD44/CK8/14. This suggests that hedgehog pathway may induce differentiation of prostate stem/progenitor cells into CD44(+)/P63(+/-) hyperplasia basal cells [112]. Other studies on DNA damage and proliferation markers p2 $7^{\text {Kip1 }}$, cyclin D3, and Ki-67, revealed interesting findings. It has been shown that $\mathrm{p} 27^{\mathrm{Kip} 1}$ is significantly upregulated in $\mathrm{BPH}$, 
TABLE 1: Molecular alterations in BPH and PCa.

\begin{tabular}{|c|c|c|c|}
\hline Factors & Normal prostate & $\mathrm{BPH}$ & $\mathrm{PCa}$ \\
\hline \multicolumn{4}{|l|}{ Prostate-specific factors } \\
\hline $5 \alpha$ reductase & Normal & Upregulated & Upregulated \\
\hline Androgen receptor (AR) & Normal & Upregulated & Upregulated \\
\hline AR coactivator & Normal & Upregulated & Upregulated \\
\hline Androgen corepressor & Normal & Upregulated & Upregulated \\
\hline PSA level in serum & $(0-4 \mathrm{ng} / \mathrm{mL})$ & $(2-8 \mathrm{ng} / \mathrm{mL})$ & $(4-10 \mathrm{ng} / \mathrm{mL})$ \\
\hline Growth factors & $\begin{array}{l}\text { FGF-2,7,9 } \\
\text { IGF } 1,2 \\
\text { IGFBP-2 }\end{array}$ & $\begin{array}{l}\text { FGF } 1,2,9 \\
\text { IGF-2 high } \\
\text { IGFBP-3 }\end{array}$ & $\begin{array}{l}\text { FGF-1,2,6,8 } \\
\text { IGF-1 high } \\
\text { IGFBP-2 high } \\
\text { IGFBP-3 high }\end{array}$ \\
\hline NE cells & Normal & Number decrease & Number increase \\
\hline \multirow{3}{*}{ Luminal cell factors } & Vimentin & Vimentin increase & Vimentin over exp \\
\hline & Intracellular space normal & Intracellular space increase & Intracellular space decrease \\
\hline & PMSA normal & PMSA decrease & PMSA increase \\
\hline Basal cells & Present & Present & Absent \\
\hline \multirow{4}{*}{ Stromal cell factor } & Fibroblast content normal & Fibroblast content increase & Fibroblast content increase \\
\hline & NMMHC & NMMHC increase & NMMHC \\
\hline & Elastin & Elastin decrease & Elastin increase \\
\hline & SMMHC & SMMHC decrease & SMMHC decrease \\
\hline Stem cell markers & $\begin{array}{c}\text { CD44, P63, Sca-1, CD133, CD117, } \\
\text { Trop2, CD49f, p27 }{ }^{\text {Kipl } 1}, \text { CK5 }(+), \\
\text { 8(-), PSCA }\end{array}$ & $\begin{array}{c}\text { CD44, p63, Sca-1, CD133, p27 } \\
\text { CD117, Trop2, CD49f, AR, } \\
\text { CK5(+), 8(-), PSCA high }\end{array}$ & $\begin{array}{c}\text { CD44, Sca-1, CD133, } \\
\text { CD117, Trop2, CD49f, CK5(-), PSCA } \\
\text { high, AR }\end{array}$ \\
\hline
\end{tabular}

whereas it is downregulated in PCa. In addition to downregulation of $\mathrm{p} 27^{\mathrm{Kip} 1}$, there is also up regulation of $\mathrm{Ki}-67$ and cyclin D3 in PCa [113].

Several lines of evidence have been indicated that CSCs exhibit both stem cells and cancer cells characteristics. CSCs have the ability to form tumors when transplanted into an animal host. CSCs can be distinguished from other cells within the tumor by cell division and alterations in their gene expression profile [114].

Advanced prostate cancer is androgen independent and basal cells can be phenotypically identified in the majority of metastases [115]. Studies from several investigators revealed that tumor-initiating cells are negative for AR and p63 and expressed the stem cell markers Oct-4, Nanog, Sox-2, Nestin, CD44, CD133, and CD117. Moreover, Sca-1-positive cells having the ability with prostate-regeneration activity, showed evidence of a basal and luminal lineage [96, 100, 116, 117]. Gu et al. demonstrated human telomerase reverse transcriptase(hTERT-) positive epithelial cells could regenerate tumor in mice that resembled the original tumor in patients [118]. These finding may be indicative of CSC role in prostate cancer.

The growing understanding of the prostate stem cell biology provides the rationale for acute approaches. But without a clear definition of stem cells in normal prostate and $\mathrm{BPH} / \mathrm{PCa}$, it is difficult to determine whether the cancer cell of origin in prostate is a stem cell, multipotent progenitor/TA cells, or a more differentiated progeny. Nonetheless, evidence exists that the cellular origin can include both basal and luminal cells.

\section{Conclusion}

The prostate stem cells are a key role player in prostate tumourigenesis and enlargement disorders. But their precise role in disease pathogenesis remains unknown. The prostate stromal and epithelial compartments and their reciprocal paracrine and autocrine interactions are crucial regulators of prostatic tissue homeostasis. The combination of the prostatic cell surface markers, such as Sca-1, CD133, p63, and CD49f, can aid in the identification of prostate stem cell populations. However, a prostate-specific stem cell marker has yet to be identified. The study of CSCs is still in its early stages. No standard treatments have yet been developed as a result of research on CSCs. The isolation and characterization of epithelial, stromal stem cells and cancer stem cells in the prostate will lead to understanding normal stem cells and CSCs activity to identify new strategies for the control of prostate diseases without harming normal cells milieu.

\section{References}

[1] M. L. Gaynor, "Isoflavones and the prevention and treatment of prostate disease: is there a role?" Cleveland Clinic Journal of Medicine, vol. 70, no. 3, pp. 203-204, 2003.

[2] L. Denis, M. S. Morton, and K. Griffiths, "Diet and its preventive role in prostatic disease," European Urology, vol. 35, no. 5-6, pp. 377-387, 1999.

[3] A. Jemal, R. Siegel, E. Ward, Y. Hao, J. Xu, and M. J. Thun, "Cancer statistics, 2009," CA Cancer Journal for Clinicians, vol. 59, no. 4, pp. 225-249, 2009. 
[4] M. M. Shen and C. Abate-Shen, "Molecular genetics of prostate cancer: new prospects for old challenges," Genes and Development, vol. 24, no. 18, pp. 1967-2000, 2010.

[5] W. W. Barclay, R. D. Woodruff, M. C. Hall, and S. D. Cramer, "A system for studying epithelial-stromal interactions reveals distinct inductive abilities of stromal cells from benign prostatic hyperplasia and prostate cancer," Endocrinology, vol. 146, no. 1, pp. 13-18, 2005.

[6] S. M. Harman, E. J. Metter, J. D. Tobin, J. Pearson, and M. R. Blackman, "Longitudinal effects of aging on serum total and free testosterone levels in healthy men," Journal of Clinical Endocrinology and Metabolism, vol. 86, no. 2, pp. 724-731, 2001.

[7] J. C. Nickel, J. Downey, I. Young, and S. Boag, "Asymptomatic inflammation and/or infection in benign prostatic hyperplasia," BJU International, vol. 84, no. 9, pp. 976-981, 1999.

[8] J. D. McConnell, "The pathophysiology of benign prostatic hyperplasia," Journal of Andrology, vol. 12, no. 6, pp. 356-363, 1991.

[9] M. Mimeault and S. K. Batra, "Recent advances on multiple tumorigenic cascades involved in prostatic cancer progression and targeting therapies," Carcinogenesis, vol. 27, no. 1, pp. 1-22, 2006.

[10] M. Marcelli and G. R. Cunningham, "Hormonal signaling in prostatic hyperplasia and neoplasia," Journal of Clinical Endocrinology and Metabolism, vol. 84, no. 10, pp. 3463-3468, 1999.

[11] A. Y. Nikitin, A. Matoso, and P. Roy-Burman, "Prostate stem cells and cancer," Histology and histopathology, vol. 22, no. 9, pp. 1043-1049, 2007.

[12] M. Notara and A. Ahmed, "Benign prostate hyperplasia and stem cells: a new therapeutic opportunity," Cell Biology and Toxicology, vol. 28, no. 6, pp. 435-442, 2012.

[13] G. L. Powers and P. C. Marker, "Recent advances in prostate development and links to prostatic diseases," Wiley Interdisciplinary Reviews, vol. 5, no. 2, pp. 243-256, 2013.

[14] G. S. Prins and O. Putz, "Molecular signaling pathways that regulate prostate gland development," Differentiation, vol. 76, no. 6, pp. 641-659, 2008.

[15] Y. Sugimura, G. R. Cunha, and A. A. Donjacour, "Morphogenesis of ductal networks in the mouse prostate," Biology of Reproduction, vol. 34, no. 5, pp. 961-971, 1986.

[16] J. E. McNeal, "Anatomy of the prostate and morphogenesis of BPH," Progress in Clinical and Biological Research, vol. 145, pp. 27-53, 1984.

[17] J. E. McNeal and D. G. Bostwick, "Anatomy of the prostatic urethra," Journal of the American Medical Association, vol. 251, no. 7, pp. 890-891, 1984.

[18] B. G. Timms, "Prostate development: a historical perspective," Differentiation, vol. 76, no. 6, pp. 565-577, 2008.

[19] C. Abate-Shen and M. M. Shen, "Molecular genetics of prostate cancer," Genes and Development, vol. 14, no. 19, pp. 2410-2434, 2000.

[20] G. Bartsch and H. P. Rohr, "Comparative light and electron microscopic study of the human, dog and rat prostate: an approach to an experimental model for human benign prostatic hyperplasia (light and electron microscopic analysis): a review," Urologia Internationalis, vol. 35, no. 2, pp. 91-104, 1980.

[21] H. Bonkhoff and K. Remberger, "Widespread distribution of nuclear androgen receptors in the basal cell layer of the normal and hyperplastic human prostate," Virchows Archiv, vol. 422, no. 1, pp. 35-38, 1993.
[22] Y. Wang, S. W. Hayward, M. Cao, K. A. Thayer, and G. R. Cunha, "Cell differentiation lineage in the prostate," Differentiation, vol. 68, no. 4-5, pp. 270-279, 2001.

[23] R. M. Long, C. Morrissey, J. M. Fitzpatrick, and R. W. G. Watson, "Prostate epithelial cell differentiation and its relevance to the understanding of prostate cancer therapies," Clinical Science, vol. 108, no. 1, pp. 1-11, 2005.

[24] A. M. De Marzo, A. K. Meeker, J. I. Epstein, and D. S. Coffey, "Prostate stem cell compartments: expression of the cell cycle inhibitor p27(Kip1) in normal, hyperplastic, and neoplastic cells," The American Journal of Pathology, vol. 153, no. 3, pp. 911919, 1998.

[25] H. Bonkhoff, U. Stein, and K. Remberger, "Endocrine-paracrine cell types in the prostate and prostatic adenocarcinoma are postmitotic cells," Human Pathology, vol. 26, no. 2, pp. 167-170, 1995.

[26] J. A. Schalken and G. van Leenders, "Cellular and molecular biology of the prostate: stem cell biology," Urology, vol. 62, supplement 1, no. 5, pp. 11-20, 2003.

[27] G. P. Amorino and S. J. Parsons, "Neuroendocrine cells in prostate cancer," Critical Reviews in Eukaryotic Gene Expression, vol. 14, no. 4, pp. 287-300, 2004.

[28] P. A. Abrahamsson, "Neuroendocrine differentiation in prostatic carcinoma," Prostate, vol. 39, no. 2, pp. 135-148, 1999.

[29] H. Bonkhoff, U. Stein, and K. Remberger, "Multidirectional differentiation in the normal, hyperplastic, and neoplastic human prostate: simultaneous demonstration of cell-specific epithelial markers," Human Pathology, vol. 25, no. 1, pp. 42-46, 1994.

[30] H. Bonkhoff and K. Remberger, "Differentiation pathways and histogenetic aspects of normal and abnormal prostatic growth: a stem cell model," Prostate, vol. 28, no. 2, pp. 98-106, 1996.

[31] Y. Xue, F. Smedts, F. M. Debruyne, J. J. de la Rosette, and J. A. Schalken, "Identification of intermediate cell types by keratin expression in the developing human prostate," Prostate, vol. 34, no. 4, pp. 292-301, 1998.

[32] D. L. Hudson, M. O'Hare, F. M. Watt, and J. R. W. Masters, "Proliferative heterogeneity in the human prostate: evidence for epithelial stem cells," Laboratory Investigation, vol. 80, no. 8, pp. 1243-1250, 2000.

[33] T. Takao and A. Tsujimura, "Prostate stem cells: the niche and cell markers," International Journal of Urology, vol. 15, no. 4, pp. 289-294, 2008.

[34] J. T. Isaacs and D. S. Coffey, "Etiology and disease process of benign prostatic hyperplasia," Prostate, vol. 2, pp. 33-50, 1989.

[35] H. F. English, R. J. Santen, and J. T. Isaacs, "Response of glandular versus basal rat ventral prostatic epithelial cells to androgen withdrawal and replacement," Prostate, vol. 11, no. 3, pp. 229242, 1987.

[36] G. S. Evans and J. A. Chandler, "Cell proliferation studies in the rat prostate: II. The effects of castration and androgeninduced regeneration upon basal and secretory cell proliferation," Prostate, vol. 11, no. 4, pp. 339-351, 1987.

[37] A. P. M. Verhagen, T. W. Aalders, F. C. S. Ramaekers, F. M. J. Debruyne, and J. A. Schalken, "Differential expression of keratins in the basal and luminal compartments of rat prostatic epithelium during degeneration and regeneration," Prostate, vol. 13, no. 1, pp. 25-38, 1988.

[38] D. P. DeKlerk and D. S. Coffey, "Quantitative determination of prostatic epithelial and stromal hyperplasia by a new technique. Biomorphometrics," Investigative Urology, vol. 16, no. 3, pp. 240-245, 1978. 
[39] N. Kyprianou and J. T. Isaacs, "Identification of a cellular receptor for transforming growth factor- $\beta$ in rat ventral prostate and its negative regulation by androgens," Endocrinology, vol. 123, no. 4, pp. 2124-2131, 1988.

[40] M. Montpetit, P. Abrahams, A. F. Clark, and M. Tenniswood, "Androgen-independent epithelial cells of the rat ventral prostate," Prostate, vol. 12, no. 1, pp. 13-28, 1988.

[41] L. Xin, H. Ide, Y. Kim, P. Dubey, and O. N. Witte, "In vivo regeneration of murine prostate from dissociated cell populations of postnatal epithelia and urogenital sinus mesenchyme," Proceedings of the National Academy of Sciences of the United States of America, vol. 100, supplement 1, pp. 11896-11903, 2003.

[42] M. Azuma, A. Hirao, K. Takubo, I. Hamaguchi, T. Kitamura, and T. Suda, "A quantitative matrigel assay for assessing repopulating capacity of prostate stem cells," Biochemical and Biophysical Research Communications, vol. 338, no. 2, pp. 1164-1170, 2005.

[43] A. Tsujimura, Y. Koikawa, S. Salm et al., "Proximal location of mouse prostate epithelial stem cells: a model of prostatic homeostasis," Journal of Cell Biology, vol. 157, no. 7, pp. 1257-1265, 2002.

[44] K. Goto, S. N. Salm, S. Coetzee et al., "Proximal prostatic stem cells are programmed to regenerate a proximal-distal ductal axis," Stem Cells, vol. 24, no. 8, pp. 1859-1868, 2006.

[45] J. A. Nemeth and C. Lee, "Prostatic ductal system in rats: regional variation in stromal organization," Prostate, vol. 28, no. 2, pp. 124-128, 1996.

[46] J. A. Nemeth, J. A. Sensibar, R. R. White, D. J. Zelner, I. Y. Kim, and C. Lee, "Prostatic ductal system in rats: tissue-specific expression and regional variation in stromal distribution of transforming growth factor-beta 1," Prostate, vol. 33, no. 1, pp. 64-71, 1997.

[47] S. N. Salm, P. E. Burger, S. Coetzee, K. Goto, D. Moscatelli, and E. L. Wilson, "TGF- $\beta$ maintains dormancy of prostatic stem cells in the proximal region of ducts," Journal of Cell Biology, vol. 170, no. 1, pp. 81-90, 2005.

[48] P. E. Burger, X. Xiong, S. Coetzee et al., "Sca-1 expression identifies stem cells in the proximal region of prostatic ducts with high capacity to reconstitute prostatic tissue," Proceedings of the National Academy of Sciences of the United States of America, vol. 102, no. 20, pp. 7180-7185, 2005.

[49] D. A. Lawson, L. Xin, R. U. Lukacs, D. Cheng, and O. N. Witte, "Isolation and functional characterization of murine prostate stem cells," Proceedings of the National Academy of Sciences of the United States of America, vol. 104, no. 1, pp. 181-186, 2007.

[50] K. G. Leong, B.-E. Wang, L. Johnson, and W.-Q. Gao, "Generation of a prostate from a single adult stem cell," Nature, vol. 456, no. 7223, pp. 804-810, 2008.

[51] A. T. Collins, F. K. Habib, N. J. Maitland, and D. E. Neal, "Identification and isolation of human prostate epithelial stem cells based on $\alpha 2 \beta 1$-integrin expression," Journal of Cell Science, vol. 114, no. 21, pp. 3865-3872, 2001.

[52] G. D. Richardson, C. N. Robson, S. H. Lang, D. E. Neal, N. J. Maitland, and A. T. Collins, "CD133, a novel marker for human prostatic epithelial stem cells," Journal of Cell Science, vol. 117, no. 16, pp. 3539-3545, 2004.

[53] M. Schmelz, R. Moll, U. Hesse et al., "Identification of a stem cell candidate in the normal human prostate gland," European Journal of Cell Biology, vol. 84, no. 2-3, pp. 341-354, 2005.

[54] E. Missol-Kolka, J. Karbanová, P. Janich et al., "Prominin-1 (CD133) is not restricted to stem cells located in the basal compartment of murine and human prostate," Prostate, vol. 71, no. 3, pp. 254-267, 2011.

[55] R. I. Bhatt, M. D. Brown, C. A. Hart et al., "Novel method for the isolation and characterisation of the putative prostatic stem cell," Cytometry A, vol. 54, no. 2, pp. 89-99, 2003.

[56] P. E. Burger, R. Gupta, X. Xiong et al., "High aldehyde dehydrogenase activity: a novel functional marker of murine prostate stem/progenitor cells," Stem Cells, vol. 27, no. 9, pp. 2220-2228, 2009.

[57] A. S. Goldstein, D. A. Lawson, D. Cheng, W. Sun, I. P. Garraway, and O. N. Witte, "Trop2 identifies a subpopulation of murine and human prostate basal cells with stem cell characteristics," Proceedings of the National Academy of Sciences of the United States of America, vol. 105, no. 52, pp. 20882-20887, 2008.

[58] A. Y. Liu, L. D. True, L. Latray et al., "Cell-cell interaction in prostate gene regulation and cytodifferentiation," Proceedings of the National Academy of Sciences of the United States of America, vol. 94, no. 20, pp. 10705-10710, 1997.

[59] J. C. Pignon, C. Grisanzio, Y. Geng, J. Song, R. A. Shivdasani, and S. Signoretti, "p63-expressing cells are the stem cells of developing prostate, bladder, and colorectal epithelia," Proceedings of the National Academy of Sciences of the United States of America, vol. 110, no. 20, pp. 8105-8110, 2013.

[60] M. Yao, R. A. Taylor, M. G. Richards et al., "Prostate-regenerating capacity of cultured human adult prostate epithelial cells," Cells Tissues Organs, vol. 191, no. 3, pp. 203-212, 2010.

[61] I. P. Garraway, W. Sun, C. P. Tran et al., "Human prostate sphereforming cells represent a subset of basal epithelial cells capable of glandular regeneration in vivo," Prostate, vol. 70, no. 5, pp. 491-501, 2010.

[62] G. van Leenders, H. Dijkman, C. Hulsbergen-van de Kaa, D. Ruiter, and J. Schalken, "Demonstration of intermediate cells during human prostate epithelial differentiation in situ and in vitro using triple-staining confocal scanning microscopy," Laboratory Investigation, vol. 80, no. 8, pp. 1251-1258, 2000.

[63] W. W. Barclay, L. S. Axanova, W. Chen et al., "Characterization of adult prostatic progenitor/stem cells exhibiting self-renewal and multilineage differentiation," Stem Cells, vol. 26, no. 3, pp. 600-610, 2008.

[64] R. A. Taylor, R. Toivanen, and G. P. Risbridger, "Stem cells in prostate cancer: treating the root of the problem," EndocrineRelated Cancer, vol. 17, no. 4, pp. R273-R285, 2010.

[65] C. G. Roehrborn, J. D. McConnell, M. Lieber et al., "Serum prostate-specific antigen concentration is a powerful predictor of acute urinary retention and need for surgery in men with clinical benign prostatic hyperplasia," Urology, vol. 53, no. 3, pp. 473-480, 1999.

[66] M. J. Naslund and M. Miner, "A review of the clinical efficacy and safety of $5 \alpha$-reductase inhibitors for the enlarged prostate," Clinical Therapeutics, vol. 29, no. 1, pp. 17-25, 2007.

[67] P. Boyle, C. Roehrborn, R. Harkaway, J. Logie, J. de La Rosette, and M. Emberton, "5-alpha reductase inhibition provides superior benefits to alpha blockade by preventing AUR and BPHrelated surgery," European Urology, vol. 45, no. 5, pp. 620-627, 2004.

[68] V. K. Lin, S.-Y. Wang, D. V. Vazquez, C. C. Xu, S. Zhang, and L. Tang, "Prostatic stromal cells derived from benign prostatic hyperplasia specimens possess stem cell like property," Prostate, vol. 67 , no. 12 , pp. $1265-1276,2007$. 
[69] G. R. Cunha, S. W. Hayward, R. Dahiya, and B. A. Foster, "Smooth muscle-epithelial interactions in normal and neoplastic prostatic development," Acta Anatomica, vol. 155, no. 1, pp. 63-72, 1996.

[70] C. Richard, G. Kim, Y. Koikawa et al., "Androgens modulate the balance between VEGF and angiopoietin expression in prostate epithelial and smooth muscle cells," Prostate, vol. 50, no. 2, pp. 83-91, 2002.

[71] G. A. Schuster and T. G. Schuster, "The relative amount of epithelium, muscle, connective tissue and lumen in prostatic hyperplasia as a function of the mass of tissue resected," Journal of Urology, vol. 161, no. 4, pp. 1168-1173, 1999.

[72] J. Tang and J. Yang, "Etiopathogenesis of benign prostatic hypeprlasia," Indian Journal of Urology, vol. 25, no. 3, pp. 312317, 2009.

[73] S. J. Berry, D. S. Coffey, J. D. Strandberg, and L. L. Ewing, "Effect of age, castration, and testosterone replacement on the development and restoration of canine benign prostatic hyperplasia," Prostate, vol. 9, no. 3, pp. 295-302, 1986.

[74] N. Kyprianou, H. Tu, and S. C. Jacobs, "Apoptotic versus proliferative activities in human benign prostatic hyperplasia," Human Pathology, vol. 27, no. 7, pp. 668-675, 1996.

[75] E. Shapiro, M. J. Becich, V. Hartanto, and H. Lepor, "The relative proportion of stromal and epithelial hyperplasia is related to the development of symptomatic benign prostate hyperplasia," Journal of Urology, vol. 147, no. 5, pp. 1293-1297, 1992.

[76] J. A. Ceder, L. Jansson, R. A. Ehrnström, L. Rönnstrand, and P.-A. Abrahamsson, "The characterization of epithelial and stromal subsets of candidate stem/progenitor cells in the human adult prostate," European Urology, vol. 53, no. 3, pp. 524-532, 2008.

[77] M. Imura, Y. Kojima, Y. Kubota et al., "Regulation of cell proliferation through a KIT-mediated mechanism in benign prostatic hyperplasia," Prostate, vol. 72, no. 14, pp. 1506-1513, 2012.

[78] A. Lammie, M. Drobnjak, W. Gerald, A. Saad, R. Cote, and C. Cordon-Cardo, "Expression of c-kit and kit ligand proteins in normal human tissues," Journal of Histochemistry and Cytochemistry, vol. 42, no. 11, pp. 1417-1425, 1994.

[79] A. Shafik, I. Shafik, and O. El-Sibai, "Identification of c-kitpositive cells in the human prostate: the interstitial cells of Cajal," Archives of Andrology, vol. 51, no. 5, pp. 345-351, 2005.

[80] A. Kondi-Pafiti, N. Arkadopoulos, C. Gennatas, V. Michalaki, M. Frangou-Plegmenou, and P. Chatzipantelis, "Expression of c-kit in common benign and malignant breast lesions," Tumori, vol. 96, no. 6, pp. 978-984, 2010.

[81] R. Simak, P. Capodieci, D. W. Cohen et al., "Expression of ckit and kit-ligand in benign and malignant prostatic tissues," Histology and Histopathology, vol. 15, no. 2, pp. 365-374, 2000.

[82] H. Yamamoto, J. R. Masters, P. Dasgupta et al., "CD49f is an efficient marker of monolayer- and spheroid colony-forming cells of the benign and malignant human prostate," PLOS ONE, vol. 7, no. 10, Article ID e46979, 2012.

[83] M. F. Pittenger, A. M. Mackay, S. C. Beck et al., "Multilineage potential of adult human mesenchymal stem cells," Science, vol. 284, no. 5411, pp. 143-147, 1999.

[84] C. Le Magnen, L. Bubendorf, C. Ruiz et al., "Klf4 transcription factor is expressed in the cytoplasm of prostate cancer cells," European Journal of Cancer, vol. 49, no. 4, pp. 955-963, 2013.

[85] A. Jemal, F. Bray, M. M. Center, J. Ferlay, E. Ward, and D. Forman, "Global cancer statistics," CA Cancer Journal for Clinicians, vol. 61, no. 2, pp. 69-90, 2011.
[86] N. J. Maitland and A. Collins, "A tumour stem cell hypothesis for the origins of prostate cancer," BJU International, vol. 96, no. 9, pp. 1219-1223, 2005.

[87] N. J. Maitland, F. M. Frame, E. S. Polson, J. L. Lewis, and A. T. Collins, "Prostate cancer stem cells: do they have a basal or luminal phenotype?" Hormones and Cancer, vol. 2, no. 1, pp. 4761, 2011.

[88] E. E. Oldridge, D. Pellacani, A. T. Collins, and N. J. Maitland, "Prostate cancer stem cells: are they androgen-responsive?" Molecular and Cellular Endocrinology, vol. 360, no. 1-2, pp. 1424, 2011.

[89] D. F. Gleason, "Classification of prostatic carcinomas," Cancer Chemotherapy Reports, vol. 50, no. 3, pp. 125-128, 1966.

[90] C. Grisanzio and S. Signoretti, "p63 in prostate biology and pathology," Journal of Cellular Biochemistry, vol. 103, no. 5, pp. 1354-1368, 2008.

[91] Z. A. Wang and M. M. Shen, "Revisiting the concept of cancer stem cells in prostate cancer," Oncogene, vol. 30, no. 11, pp. 12611271, 2011.

[92] H. Korsten, A. Ziel-van der Made, X. Ma, T. van der Kwast, and J. Trapman, "Accumulating progenitor cells in the luminal epithelial cell layer are candidate tumor initiating cells in a Pten knockout mouse prostate cancer model," PLoS ONE, vol. 4, no. 5, Article ID e5662, 2009.

[93] X. Ma, A. C. Ziel-van der Made, B. Autar et al., "Targeted biallelic inactivation of Pten in the mouse prostate leads to prostate cancer accompanied by increased epithelial cell proliferation but not by reduced apoptosis," Cancer Research, vol. 65, no. 13, pp. 5730-5739, 2005.

[94] D. J. Mulholland, L. Xin, A. Morim, D. Lawson, O. Witte, and H. Wu, "Lin-Sca-1+CD49fhigh stem/progenitors are tumorinitiating cells in the Pten-null prostate cancer model," Cancer Research, vol. 69, no. 22, pp. 8555-8562, 2009.

[95] A. S. Goldstein, J. Huang, C. Guo, I. P. Garraway, and O. N. Witte, "Identification of a cell of origin for human prostate cancer," Science, vol. 329, no. 5991, pp. 568-571, 2010.

[96] A. T. Collins, P. A. Berry, C. Hyde, M. J. Stower, and N. J. Maitland, "Prospective identification of tumorigenic prostate cancer stem cells," Cancer Research, vol. 65, no. 23, pp. 1094610951, 2005.

[97] C. van den Hoogen, G. van der Horst, H. Cheung et al., "High aldehyde dehydrogenase activity identifies tumor-initiating and metastasis-initiating cells in human prostate cancer," Cancer Research, vol. 70, no. 12, pp. 5163-5173, 2010.

[98] E. M. Hurt, B. T. Kawasaki, G. J. Klarmann, S. B. Thomas, and W. L. Farrar, "CD44+CD24- prostate cells are early cancer progenitor/stem cells that provide a model for patients with poor prognosis," British Journal of Cancer, vol. 98, no. 4, pp. 756765, 2008.

[99] C. Wei, W. Guomin, L. Yujun, and Q. Ruizhe, "Cancer stem-like cells in human prostate carcinoma cells DU145: the seeds of the cell line?" Cancer Biology and Therapy, vol. 6, no. 5, pp. 763-768, 2007.

[100] L. Patrawala, T. Calhoun, R. Schneider-Broussard et al., "Highly purified CD44+ prostate cancer cells from xenograft human tumors are enriched in tumorigenic and metastatic progenitor cells," Oncogene, vol. 25, no. 12, pp. 1696-1708, 2006.

[101] V. K. Rajasekhar, L. Studer, W. Gerald, N. D. Socci, and H. I. Scher, "Tumour-initiating stem-like cells in human prostate cancer exhibit increased NF- $\kappa$ B signalling," Nature Communications, vol. 2, article 162, 2011. 
[102] A. D. Whetton and G. J. Graham, "Homing and mobilization in the stem cell niche," Trends in Cell Biology, vol. 9, no. 6, pp. 233-238, 1999.

[103] A. Spradling, D. Drummond-Barbosa, and T. Kai, "Stem cells find their niche," Nature, vol. 414, no. 6859, pp. 98-104, 2001.

[104] I. V. Litvinov, D. J. Vander Griend, Y. Xu, L. Antony, S. L. Dalrymple, and J. T. Isaacs, "Low-calcium serum-free defined medium selects for growth of normal prostatic epithelial stem cells," Cancer Research, vol. 66, no. 17, pp. 8598-8607, 2006.

[105] J. T. Isaacs, "Prostate stem cells and benign prostatic hyperplasia," Prostate, vol. 68, no. 9, pp. 1025-1034, 2008.

[106] D. L. Hudson, "Epithelial stem cells in human prostate growth and disease," Prostate Cancer and Prostatic Diseases, vol. 7, no. 3, pp. 188-194, 2004.

[107] C. P. Tran, C. Lin, J. Yamashiro, and R. E. Reiter, "Prostate stem cell antigen is a marker of late intermediate prostate epithelial cells," Molecular Cancer Research, vol. 1, no. 2, pp. 113-121, 2002.

[108] P. A. Humphrey, "Diagnosis of adenocarcinoma in prostate needle biopsy tissue," Journal of Clinical Pathology, vol. 60, no. 1, pp. 35-42, 2007.

[109] C. J. Shepherd, S. Rizzo, I. Ledaki et al., "Expression profiling of CD133+ and CD133- epithelial cells from human prostate," Prostate, vol. 68, no. 9, pp. 1007-1024, 2008.

[110] A. T. Collins and N. J. Maitland, "Prostate cancer stem cells," European Journal of Cancer, vol. 42, no. 9, pp. 1213-1218, 2006.

[111] R. Blum, R. Gupta, P. E. Burger et al., "Molecular signatures of prostate stem cells reveal novel signaling pathways and provide insights into prostate cancer," PLoS ONE, vol. 4, no. 5, Article ID e5722, 2009.

[112] B.-Y. Chen, J.-Y. Liu, H.-H. Chang et al., "Hedgehog is involved in prostate basal cell hyperplasia formation and its progressing towards tumorigenesis," Biochemical and Biophysical Research Communications, vol. 357, no. 4, pp. 1084-1089, 2007.

[113] D. Nikoleishvili, A. Pertia, O. Trsintsadze, N. Gogokhia, L. Managadze, and A. Chkhotua, "Expression of p27(Kip1), cyclin D3 and $\mathrm{Ki} 67$ in $\mathrm{BPH}$, prostate cancer and hormone-treated prostate cancer cells," International Urology and Nephrology, vol. 40, no. 4, pp. 953-959, 2008.

[114] J. M. Rosen and C. T. Jordan, "The increasing complexity of the cancer stem cell paradigm," Science, vol. 324, no. 5935, pp. 16701673, 2009.

[115] A. Y. Liu, P. S. Nelson, G. D. van Engh, and L. Hood, "Human prostate epithelial cell-type cDNA libraries and prostate expression patterns," Prostate, vol. 50, no. 2, pp. 92-103, 2002.

[116] G. J. L. H. van Leenders and J. A. Schalken, "Stem cell differentiation within the human prostate epithelium: implications for prostate carcinogenesis," BJU International, vol. 88, Supplement, no. 2, pp. 35-42, 2001.

[117] N. Craft, C. Chhor, C. Tran et al., "Evidence for clonal outgrowth of androgen-independent prostate cancer cells from androgen-dependent tumors through a two-step process," Cancer Research, vol. 59, no. 19, pp. 5030-5036, 1999.

[118] A. Gu, J. Yuan, M. Wills, and S. Kasper, "Prostate cancer cells with stem cell characteristics reconstitute the original human tumor in vivo," Cancer Research, vol. 67, no. 10, pp. 4807-4815, 2007. 

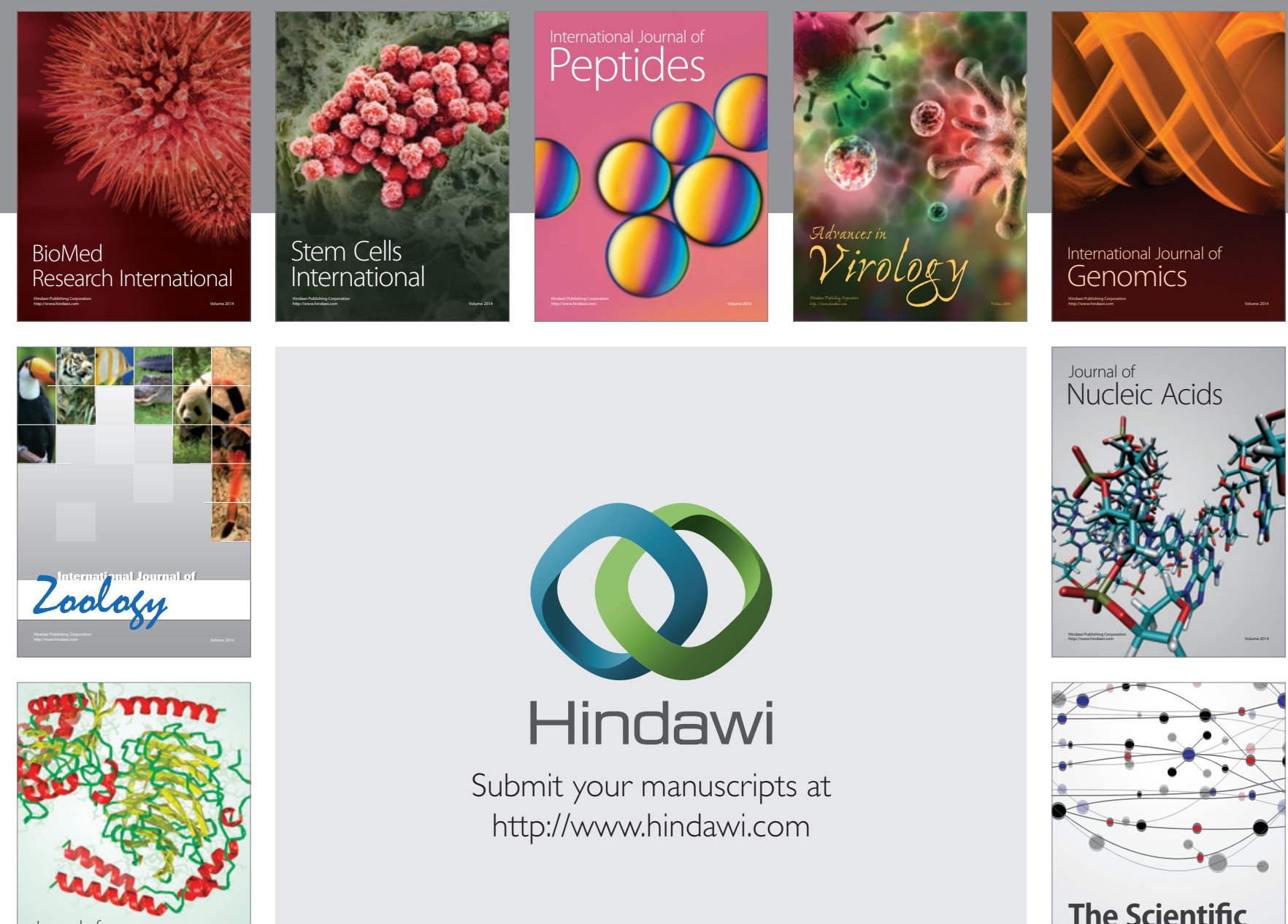

Submit your manuscripts at

http://www.hindawi.com

Journal of
Signal Transduction
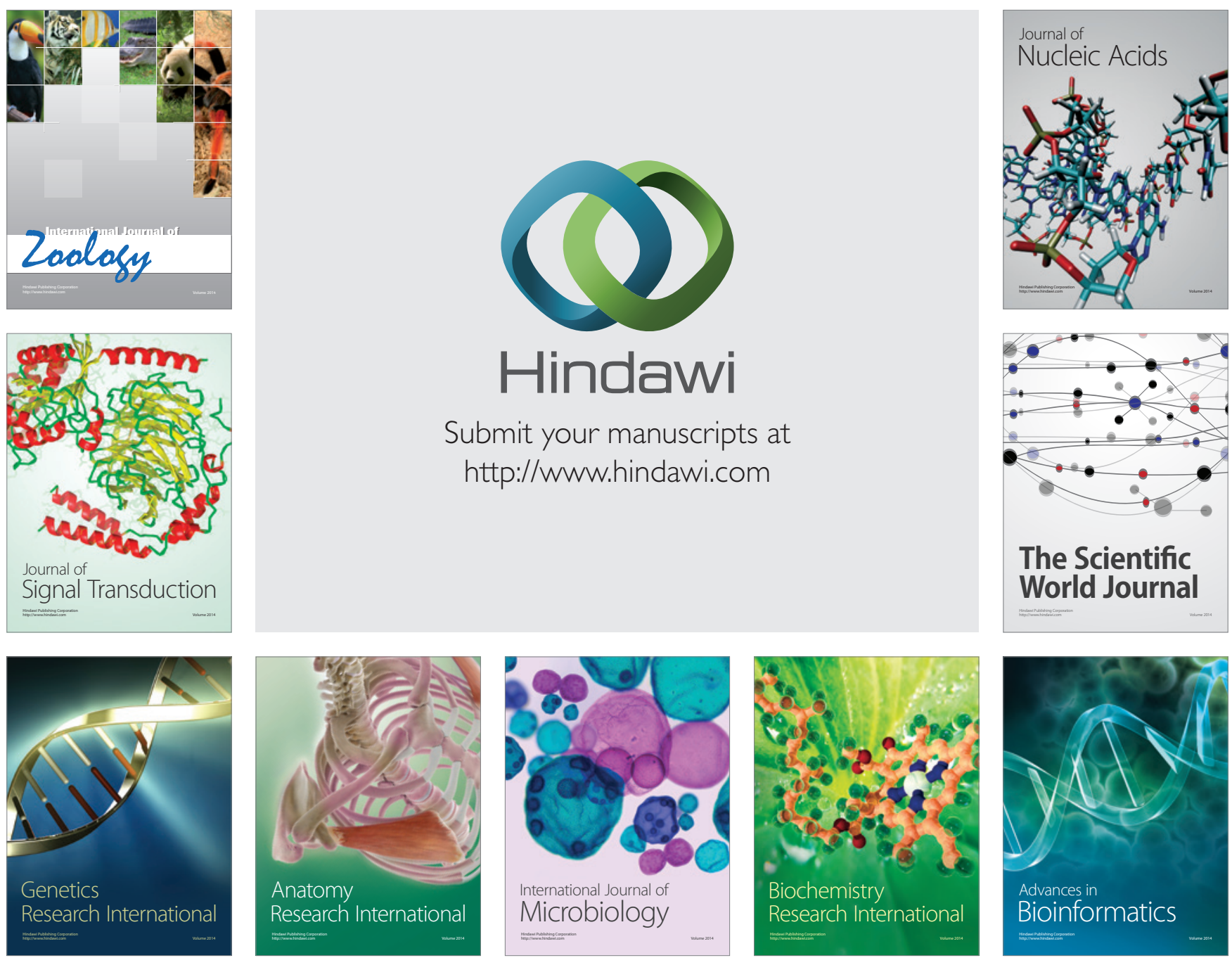

The Scientific World Journal
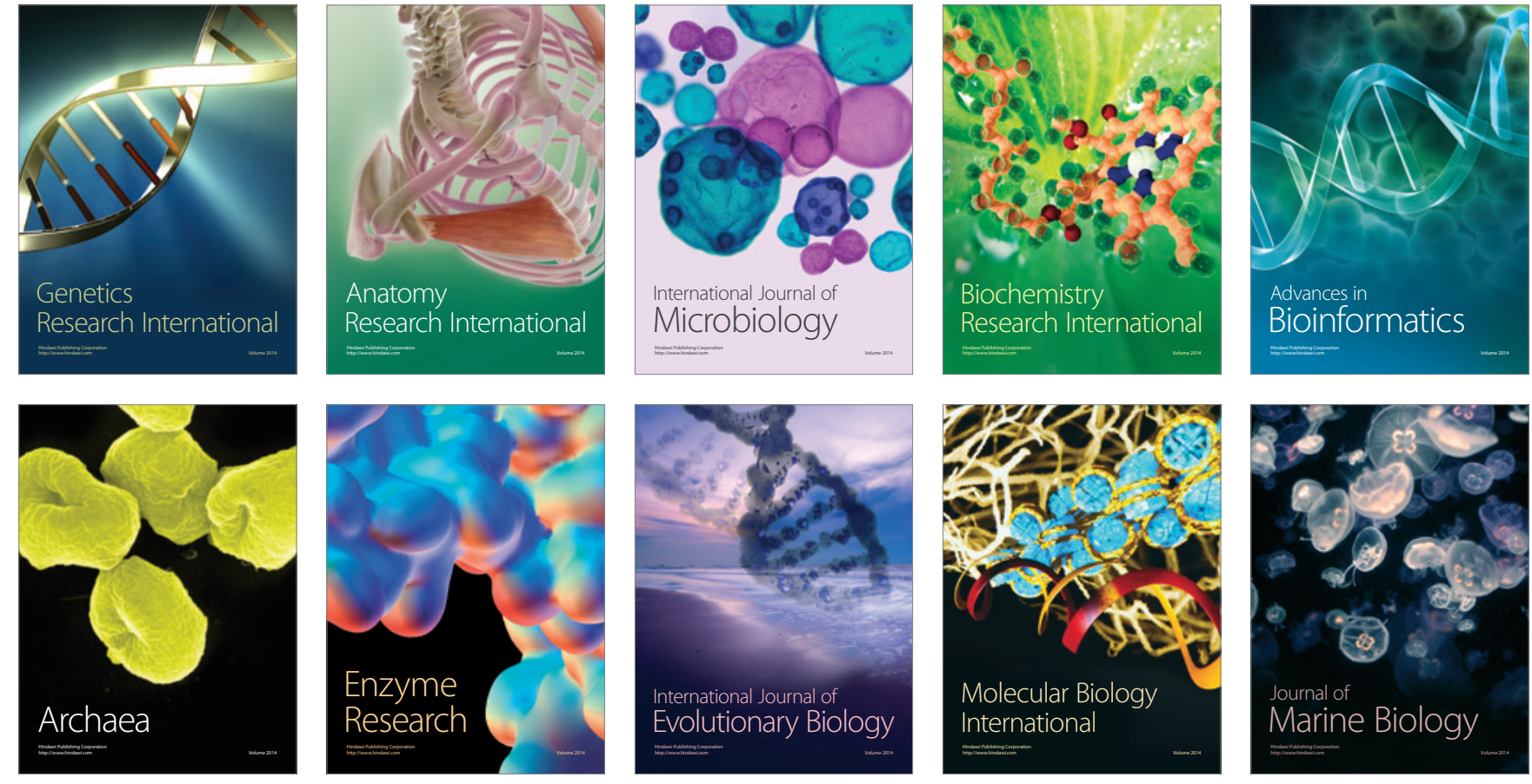